Because casts were found in all but two specimens after exercise we cannot support the view of Siegel et $a l^{8}$ that the appearance of casts after exercise should be attributed to intrinsic renal causes until proved otherwise. Whereas most subjects in the present study had hyaline or hyaline-granular casts after exercise, urine samples from 10 runners contained red-cell casts and all but one of these also had + or ++ urinary protein on dipstick testing. Two subjects showed trace amounts of urine protein before exercise and developed heavy proteinuria, high red-cell counts, and red-cell casts after exercise and may well have had underlying renal disease.

Nine runners had high cast counts before exercise, but the importance of these is uncertain. Only two of the nine developed haematuria after running, and both of these also developed proteinuria.

The present study also showed an increase in urinary nucleated-cell counts after exercise in 35 runners, and in one subject this rose to $>10^{6} \mathrm{cells} / \mathrm{ml}$. Often, however, it is not feasible to identify precisely the types of cells recorded as urinary "leucocytes," and in some cases renal tubular cells may possibly have been counted. Further study of this is warranted since if these are renal tubular cells they may be a precursor of acute tubular necrosis, which has been reported after strenuous exercise.

The results of this study confirm that increased glomerular bleeding occurs in most subjects after long-distance running. In some the haematuria may be considerable and accompanied by proteinuria and the presence of red-cell casts. We did not observe non-glomerular haematuria, and if non-glomerular haematuria develops after this degree of exercise cystoscopy may be warranted.
We thank Dr B Ihle and Sister D Saines for their help in collecting samples, and Mrs G Rosevear for typing the manuscript.

\section{References}

${ }^{1}$ Collier W. Functional albuminuria in athletes. Br Med $\mathcal{F} 1907$; i :4-6.

2 Barach JH. Physiological and pathological effects of severe exertion (the marathon race) on the circulatory and renal systems. Arch Intern Med $1910 ; 5: 382-405$.

${ }^{3}$ Barach $\mathrm{JH}$. Evidences of nephritis and urinary acidosis. Am $\mathcal{F} \mathrm{Med} S \mathrm{Si}$ 1920;159:398-402.

${ }^{4}$ Foster GS. Excessive physical exertion and its effects on the kidneys. fAMA 1939;112:801-2.

${ }^{5}$ Gardner KD Jr. "Athletic pseudonephritis". Alterations of urine sediment by athletic competition. $\mathcal{F A M A} 1956 ; 161: 1613-7$.

${ }^{6}$ Blacklock NJ. Bladder trauma in the long distance runner. " 10,000 metres hematuria". Br f Urol 1977;49:129-32.

'Fred HL, Natelson EA. Grossly bloody urine of runners. South Med $\mathcal{F}$ 1977;70:1394-6.

${ }^{8}$ Siegel AJ, Hennekens CH, Solomon HS, Van Boeckel B. Exercise related hematuria. Findings in a group of marathon runners. FAMA 1979; 241:391-2.

${ }^{9}$ Kincaid-Smith P. Quantitative counts in urine microscopy. Med $\mathcal{f}$ Aust $1979 ; 1: 605$

${ }^{10}$ Birch DF, Fairley KF. Hematuria : glomerular or non-glomerular. Lancet 1979 ;ii :845-6.

${ }^{11}$ Fairley KF, Birch DF. Hematuria: a simple method for identifying glomerular bleeding. Kidney Int $1982 ; 21: 105-8$.

${ }_{12}$ Fairley KF. Haematuria. Medicine Australia 1980;25:1781-4.

${ }^{13}$ Fassett RG, Horgan BA, Mathew TH. The detection of glomerular bleeding by phase-contrast microscopy. Lancet $1982 ; \mathrm{i}: 1432-3$.

${ }^{14}$ Fassett RG, Horgan BA, Mathew TH. The value of phase-contrast microscopy in separating glomerular from non-glomerular urinary bleeding. Aust NZ F Med 1981;11:593.

(Accepted 27 August 1982)

\title{
Alcohol abstention and premature mortality in middle-aged men
}

\author{
BO PETERSSON, ERIK TRELL, HANS KRISTENSON
}

\begin{abstract}
A series of middle-aged men were investigated for total mortality up to five years after completing a questionnaire on alcohol consumption administered during a preventive medical screening programme in Malmö, Sweden. The aim was to test the hypothesis that small amounts of alcohol are beneficial to general and cardiovascular health.

Relative mortality was increased among the men who had reported non-use of alcohol in the screening questionnaire. Most of these men, however, had chronic disease as the reason for their abstention, or even a past history of alcoholism.
\end{abstract}

\footnotetext{
Section of Preventive Medicine, Department of Internal Medicine, University of Lund, Malmö General Hospital, S-21401 Malmö, Sweden

BO PETERSSON, MD, associate researcher in preventive medicine ERIK TRELL, MD, associate professor in preventive medicine
}

Department of Alcohol Diseases, University of Lund, Malmö General Hospital, S-21401 Malmö, Sweden

HANS KRISTENSON, MD, associate professor in alcohol diseases
Increased mortality in non-drinkers may create a false impression of a preventive effect of any versus no daily drinking in relation to general and cardiovascular health.

\section{Introduction}

Several studies have suggested that small amounts of alcohol may be beneficial for general and cardiovascular health. ${ }^{1-6}$ A "cardioprotective" effect of alcohol has been postulated, mediated by, for example, decreased platelet aggregation and coagulation or increased $\alpha$-lipoprotein concentrations, or both. ${ }^{1-6}$ These studies have partly been based on comparing mortality ratios in drinkers and non-drinkers, which tend to support "a small preventive effect of any versus no drinking."2 As a group, however, "abstainers" may not represent people with a smooth continuum of non-drinking but be widely heterogeneous both in their past history of alcohol use and in their morbidity composition. For example, a substantial proportion of non-drinkers may have diagnosed or symptomatic illness as the main reason for their current abstinence, and some may be temporarily reformed alcoholics.

In a preventive medical screening programme in Malmö we administered a questionnaire on alcohol consumption ${ }^{7}$ and used biochemical markers of alcohol-related metabolic effects. ${ }^{8} \mathrm{We}$ 
report here on the increased premature mortality among men who had stated in the questionnaire that they abstained from drinking alcohol.

\section{Subjects and methods}

Screening investigations-During 1974-9 all male residents of Malmö born in 1926, 1927, 1928, 1929, 1930, 1931, and 1932 were invited to attend for screening at the department of preventive medicine at this hospital. Subjects were divided into cohorts according to year of birth and the cohorts approached consecutively. Of all 10353 men contacted, $7725(74.6 \%)$ participated. Investigations included measurements of height and weight, pulse rate, blood pressure (standing and recumbent, and before and after 10 minutes' rest), and skinfold thickness; simple pulmonary function tests; electrocardiogram; and several fasting laboratory estimations, including $\gamma$-glutamyltransferase activity. All laboratory analyses were performed according to standard methods in the department of clinical chemistry.

Questionnaire on alcohol consumption-All screening attenders answered a questionnaire containing 260 questions and presented either as an ordinary form, or as preprinted punch cards in a cardcollecting box, ${ }^{9}$ or directly by interactive computer terminals. ${ }^{\circ}$ From April 1976 nine questions on alcohol consumption (Malmö modification of brief MAST; Mm-MAST) were included. ${ }^{7}$ A tenth question "Are you a teetotaller ?" was also included to get an approximate number of abstainers in the population. The questions on alcohol consumption were included in 90 of the questionnaires given to men born in 1927 and in all of the questionnaires used for subsequent cohorts. Altogether 5410 men answered the questions on alcohol consumption (table I).

Mortality analyses-Records of deaths among the screened population up to the end of 1980 were obtained from the department of pathology, which is notified of all deaths among Malmö residents. Stated causes of death were confirmed by reviewing clinical records, necropsy reports, and police reports; all forensic necropsy reports were reviewed by one of us. Possible registration at the department of alcohol diseases was searched for and the screening protocols reviewed. All Swedes have a 10-digit identification number, which facilitates such record linkages. In classifying mortality we used our own criteria for alcohol-related death, ${ }^{10}$ which are based on the definitions of the WHO for alcohol-related disabilities. ${ }^{11}$ Hence alcoholrelated death was recorded when we could reasonably infer that alcohol was the major factor. Other deaths were classified according to standard criteria.

Statistical methods-All screening results, including the results of the questionnaires, were fed into a NOVA 830 computer for later retrieval and analysis. The results of the alcohol questionnaire were grouped into seven categories, $\mathrm{A}$ and $0-5$ (A, men reporting alcohol abstention; $0-5$, men answering yes to from none to five or more of the questions) (see table II). The total mortality and its distribution were analysed in relation to these results. Significance of differences between the various answer categories and of trend in the nonabstainers was assessed by $\chi^{2}$ test. Expected answer frequencies were obtained from a series of matched controls (see below).

\section{Results}

Of all 7725 men who were screened in the series, 127 had died by the end of 1980. For each of these we selected two living controls matched for age and date of screening and then from each group excluded those who had not been given the alcohol questionnaire. Of the remaining subjects, 82 who had died and 155 of the living controls had answered the questionnaire on alcohol consumption and form the basis of the following analysis.

Table II shows the distribution of men in the study and control groups among the seven categories of reported alcohol consumption. Overall, premature mortality was overrepresented in the total group of abstainers (seven deaths; $8.5 \%$ ) as compared with among the total group of alcohol users. Table II also shows the observed to expected ratios as determined from the study and control groups. The highest ratio $(2 \cdot 20)$ was found among subjects who had reported abstention in the questionnaire, and the lowest ratio $(0 \cdot 72)$ was found in those who had answered affirmatively to none of the questions on alcohol consumption (significance of trend in the non-abstainers $p=0.006$ ). The observed to expected ratio increased with the category of stated alcohol consumption but did not reach the ratio found among the nonusers.
Of the seven deaths among men who had reported abstinence in the questionnaire, four were caused by chronic illness (lung embolism, hepatitis, gastric cancer, gastric cancer), which in two cases (lung embolism and hepatitis) may have been related to a past history of alcoholism. The other three deaths occurred in men with malignant melanoma, epilepsy, and rheumatoid arthritis. The diagnosis was known at the time of the questionnaire in four of the cases (one of chronic alcoholism, one operated gastric cancer, one rheumatoid arthritis, treated with cytostatics, and one chronic hepatitis also treated with cytostatics).

TABLE I-Proportions of men answering "yes" to questions on alcohol consumption, and percentiles of $\gamma$-glutamyltransferase activity in each answer group

\begin{tabular}{|c|c|c|c|c|c|}
\hline \multirow{13}{*}{$\begin{array}{l}\text { (A) Are you a teetotaller? } \\
\text { (1) Do you take a drink before going } \\
\text { to a party? } \\
\text { (2) Do you usually drink a bottle of } \\
\text { wine or corresponding amount of } \\
\text { alcohol over the weekend? } \\
\text { (3) Do you drink a couple of drinks } \\
\text { (or beers) a day to relax? } \\
\text { (4) Do you tolerate more alcohol now } \\
\text { than you did } 10 \text { years ago? } \\
\text { (5) Have you difficulties not drinking } \\
\text { more than your friends? } \\
\text { (6) Do you fall asleep. after moderate } \\
\text { drinking without knowing how } \\
\text { you got to bed ? } \\
\text { (7) Do you have a bad conscience } \\
\text { after drinking? } \\
\text { (8) Do you take a drink (or a beer) } \\
\text { the day after a party? } \\
\text { (9) Do you try to avoid alcohol for a } \\
\text { determined period of time-for } \\
\text { example, a week? }\end{array}$} & \multirow{2}{*}{\multicolumn{2}{|c|}{$\begin{array}{l}\text { No }(\%) \text { of men } \\
\text { answering } \\
\text { affirmatively* }\end{array}$}} & \multicolumn{3}{|c|}{$\begin{array}{c}\gamma \text {-Glutamyltransferase } \\
\text { percentiles } \dagger\end{array}$} \\
\hline & & & \multirow{2}{*}{$\begin{array}{l}\text { P } 50 \\
0.39\end{array}$} & \multirow{2}{*}{$\frac{\text { P } 90}{0.96}$} & \multirow{2}{*}{$\frac{P 95}{1.61}$} \\
\hline & 286 & $(5 \cdot 8)$ & & & \\
\hline & 714 & $(14.5)$ & 0.51 & 1.59 & $2 \cdot 28$ \\
\hline & 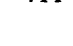 & 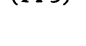 & & & 220 \\
\hline & 1122 & $(22 \cdot 7)$ & 0.49 & $1 \cdot 38$ & 2.08 \\
\hline & 240 & $(4 \cdot 8)$ & 0.67 & $2 \cdot 45$ & 4.55 \\
\hline & 395 & $(8 \cdot 0)$ & 0.47 & $1 \cdot 77$ & 2.43 \\
\hline & 137 & $(2 \cdot 8)$ & 0.49 & 1.56 & $2 \cdot 33$ \\
\hline & 227 & $(4 \cdot 6)$ & 0.51 & $1 \cdot 24$ & $1 \cdot 80$ \\
\hline & 347 & $(7 \cdot 0)$ & 0.49 & $1 \cdot 72$ & 2.49 \\
\hline & 667 & $(13 \cdot 5)$ & 0.51 & 1.52 & $2 \cdot 24$ \\
\hline & 805 & $(16 \cdot 3)$ & 0.49 & 1.49 & $2 \cdot 36$ \\
\hline
\end{tabular}

* Results shown for all 4350 men born in 1928-31 and 90 men born in 1927. Results for 950 men born in 1932 showed same distribution but are excluded from table.

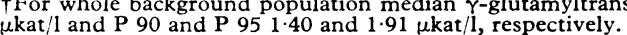

TABLE II-Distribution of men who died and of living controls among seven categories of reported alcohol consumption. Figures are number (\%) of men

\begin{tabular}{crrl}
\hline $\begin{array}{c}\text { Category of alcohol } \\
\text { consumption }\end{array}$ & $\begin{array}{c}\text { Dead } \\
(\mathrm{n}=82)\end{array}$ & $\begin{array}{c}\text { Living } \\
(\mathrm{n}=155)\end{array}$ & $\begin{array}{c}\text { Observed: expected } \\
\text { ratio }\end{array}$ \\
\hline Abstention & $7(8 \cdot 5)$ & $6(3 \cdot 9)$ & $2 \cdot 20$ \\
0 & $27(32 \cdot 9)$ & $71(45 \cdot 8)$ & $0 \cdot 72$ \\
1 & $14(17 \cdot 1)$ & $38(24 \cdot 5)$ & $0 \cdot 70\}(\mathrm{p}<0.05)$ \\
2 & $13(15 \cdot 9)$ & $20(12 \cdot 9)$ & $1 \cdot 23(\mathrm{NS})$ \\
3 & $13(15 \cdot 9)$ & $12(7 \cdot 7)$ & $2 \cdot 05(\mathrm{NS})$ \\
4 & $4(4 \cdot 9)$ & $5(3 \cdot 2)$ & \} $1 \cdot 89(\mathrm{NS})$ \\
5 & $4(4 \cdot 9)$ & $3(1 \cdot 9)$ & \\
\hline
\end{tabular}

NS $=$ Not significant

Table III gives the mean screening $\gamma$-glutamyltransferase activities in the study group in relation to the various categories of stated alcohol consumption and proportions of deaths in these categories thought to be related to alcohol. With the exclusion of deaths among abstainers that may have been related to a past history of alcoholism, both the $\gamma$-glutamyltransferase activity and the proportion of alcohol-related deaths increased with ascending category of stated alcohol consumption.

TABLE III-Categories of stated alcohol consumption and $\gamma$-glutamyltransferase activities at time of screening and proportions of alcohol-related deaths among the 82 men who died

\begin{tabular}{|c|c|c|c|}
\hline \multirow[b]{2}{*}{$\begin{array}{l}\text { Category of alcohol } \\
\text { consumption }\end{array}$} & \multirow{2}{*}{$\begin{array}{c}\text { Mean }( \pm S D) \\
\gamma \text {-glutamyltransferase } \\
\text { activity }(\mu \mathrm{kat} / \mathrm{l})\end{array}$} & \multicolumn{2}{|c|}{$\begin{array}{l}\text { Proportion } \\
\text { alcohol-related/total deaths }\end{array}$} \\
\hline & & No & $\%$ \\
\hline $\begin{array}{c}\text { Abstention } \\
0 \\
1 \\
1 \\
2 \\
3 \\
4 \\
5\end{array}$ & $\begin{array}{r}0.59 \pm 0.56 \\
0.60 \pm 0.43 \\
0.60 \pm 0.48 \\
0.72 \pm 0.63 \\
0.68 \pm 0.60 \\
0.87 \pm 0.66\end{array}$ & $\begin{array}{c}1(2) / 7 \\
1 / 27 \\
1 / 14 \\
3 / 13 \\
3 / 13 \\
3 / 4 \\
4 / 4\end{array}$ & $\begin{array}{r}14 \cdot 3(28 \cdot 6) \\
3 \cdot 7 \\
7 \cdot 1 \\
23 \cdot 1 \\
23 \cdot 1 \\
75 \cdot 0 \\
100 \cdot 0\end{array}$ \\
\hline
\end{tabular}




\section{Discussion}

Despite the small size of this series, the subjects in the study and control groups were uniform in age and sex, had been recruited consecutively, and the results were highly significant. These suggested that conclusions on cardioprotective and other beneficial effects of low alcohol consumption may stem from increased ill health among non-users of alcohol. Including such non-users in studies of mortality may therefore create an impression that low levels of alcohol consumption are associated with a more favourable health state than no consumption at all. On the contrary, however, when we excluded this second category there seemed to be a continuous relation over the whole range of self-reported alcohol consumption, premature mortality being least in the lowest alcohol intake category and increasing with category. Most dramatic was the increase in alcohol-related deaths (table III). The validity of our questionnaire method has been evaluated and confirmed in our and other population studies. ${ }^{7} \gamma$-Glutamyltransferase activity, which predominantly reflects biological effects of alcohol rather than the exact amounts consumed, ${ }^{8}$ also increased with intake category and tended to be low in the abstinent group.?

We think that the increased mortality in our abstinent group was related not to their non-use of alcohol but to the severe diseases in individual cases that made them give up alcohol in the first place. Of the seven abstainers in our study who died prematurely, four had organic diseases that might motivate abstinence from alcohol rather than be caused by alcohol. Such confounding factors will need realistic assessment in future investigations.
This work was supported by grants from the Swedish Council for Planning and Co-ordination of Research (BP) and the Swedish Delegation for Social Research, Ministry of Health and Social Affairs (HK).

\section{References}

1 Klatsky AL, Friedman GD, Siegelaub AB. Alcohol consumption before myocardial infarction. Results from the Kaiser-Permanente epidemiologic study of myocardial infarction. Ann Intern Med $1974 ; 81: 294-301$.

${ }^{2}$ Hennekens CH, Rosner B, Cole DS. Daily alcohol consumption and fatal coronary heart disease. Am $\mathcal{F}$ Epidemiol 1978;107:196-200.

${ }^{3}$ Hennekens CH, Willet W, Rosner B, Cole DS, Mayrent SL. Effects of beer, wine, and liquor in coronary deaths. $\mathcal{f} A M A$ 1979;242:1973-4.

4 LaPorte RE, Cresanta JL, Kuler LH. The relationship of alcohol consumption to atherosclerotic heart disease. Prev Med 1980;9:22-40.

${ }^{5}$ Klatsky AL, Friedman GD, Siegelaub AB. Alcohol and mortality. A tenyear Kaiser-Permanente experience. Ann Intern Med 1981;95:139-45.

6 Marmot MG, Rose G, Shipley MJ, Thomas BJ. Alcohol and mortality: a U-shaped curve. Lancet $1981 ; \mathrm{i}: 580-3$.

${ }^{7}$ Kristenson H, Trell E. Indications of alcohol consumption. Comparison between a questionnaire (Mm-MAST), interviews and serum $\gamma$-glutamyltransferase (GGT) in a health survey of middle-aged males. $\mathrm{Br} \mathcal{F}$ Addict (in press).

${ }^{8}$ Kristensson $\mathrm{H}$, Trell E, Hood B. Serum gamma-glutamyltransferase in screening and continuous control of heavy drinking in middle-aged men. Am 7 Epidemiol $1981 ; 114: 862-72$.

9 Trell E, Dahlberg N, Larsson C, et al. Interactive computer system for monitoring multiphasic health screening. Comput Programs Biomed 1980;12:262-70.

10 Petersson B, Kristensson $\mathrm{H}$, Sternby $\mathrm{NH}$, et al. Alcohol consumption and premature death in middle-aged men. $\mathrm{Br} M e d \mathcal{F} 1980$;280:1403-6.

11 Anonymous. WHO and a new perspective on alcoholism. Lancet 1977; : 1087-8.

(Accepted 9 September 1982)

\title{
Association of cold weather with testicular torsion
}

\author{
R B SHUKLA, D G KELLY, L DALY, E J GUINEY
}

\begin{abstract}
A retrospective study of 46 patients who presented with proved testicular torsion over five years at two Dublin hospitals showed that in $\mathbf{4 0}$ cases torsion had occurred when the temperature was under $2^{\circ} \mathrm{C}$; the incidence of torsion was higher during the cold months of the year. Both of these findings were statistically significant.

These and other results suggest that the ambient temperature may have some role in the incidence and aetiology of testicular torsion.
\end{abstract}

St Vincent's Hospital, Dublin 4

R B SHUKLA, MS, FRCSI, surgical registrar (now at North Middlesex Hospital, London)

D G KELLY, MCH, FRCSI, consultant surgeon

Department of Community Medicine and Epidemiology, University College, Dublin, Dublin 4

L DALY, MSc, statistician

Department of Surgery, Our Lady's Hospital for Sick Children, Dublin 12

E J GUINEY, MCH, FRCSI, professor

\section{Introduction}

Little is known about the aetiology of torsion of the testis. ${ }^{12}$ Anatomical abnormalities may predispose to the condition, and trauma is believed to be an aetiological factor ${ }^{1}$; many cases, however, occur in bed. ${ }^{3}$ In reviewing patients with testicular torsion admitted over three years to the James Connolly Memorial Hospital in Blanchardstown, the General Hospital in Nenagh, and the Adelaide and National Children's hospitals in Dublin we noted that an epidemic appeared to have occurred when the temperature was low. This observation stimulated us to investigate further the relation between torsion and variation in temperature. We report here a retrospective study of 46 patients with proved torsion of the testis treated at St Vincent's Hospital, Dublin, and the Children's Hospital, Dublin, from 1976 to 1980 carried out to investigate the effect of cold weather on torsion. The incidence of torsion, age, presenting symptoms, and rate of testicular salvage in this group of patients are reported elsewhere. ${ }^{4}$

\section{Patients, methods, and results}

We studied the records of all patients with testicular torsion admitted over the five years 1976-80. Only those in whom the diagnosis had been proved by surgical exploration were included. The exact time, day, and date of the onset of symptoms were noted on a standardised form in each case. From this information the precise weather temperature at the time testicular torsion was considered to 